\title{
The Impact of Tourism on the Local Economy in Malaysia
}

\author{
Chin-Hong Puah ${ }^{1}$, Meng-Chang Jong ${ }^{1}$, Norazirah Ayob ${ }^{1} \&$ Shafinar Ismail ${ }^{2}$ \\ ${ }^{1}$ Faculty of Economics and Business, Universiti Malaysia Sarawak, 94300 Kota Samarahan, Sarawak, Malaysia \\ ${ }^{2}$ Faculty of Business Management, Universiti Teknologi MARA Melaka, 75300 Bandaraya Melaka, Malaysia \\ Correspondence: Chin-Hong Puah, Faculty of Economics and Business, Universiti Malaysia Sarawak, 94300 \\ Kota Samarahan, Sarawak, Malaysia. Tel: 60-8258-4294. E-mail: chpuah@unimas.my
}

Received: September 10, 2018

Accepted: November 6, $2018 \quad$ Online Published: November 13, 2018

doi:10.5539/ijbm.v13n12p151

URL: https://doi.org/10.5539/ijbm.v13n12p151

\begin{abstract}
The local and international communities play an important role in the sustainable growth of the Malaysian tourism industry. The principle of sustainable growth in the tourism industry was proposed by the World Tourism Organization (WTO) in 1988. As the tourism industry is one of the largest and fastest growing industries in Malaysia, the government has poured considerable effort into promoting this industry consistent with the objective of the Economic Transformation Program (ETP) to transform from a resource-based economy to a service-based economy. This study aimed to test the hypothesis of tourism-led growth from Malaysia's perspective. The tourism revenue earned by the government can be used to invest in industry to further promote economic growth in Malaysia. Hence, tourist receipts and capital investment in the tourism industry are important factors that can affect the nation's economic growth. Utilizing Malaysian data from 1995 to 2016, the study employed the Autoregressive Distributed Lag (ARDL) approach to examine whether the tourism-led growth is valid in this study. Empirical findings indicated that both variables have a significant positive impact on economic growth and the hypothesis of tourism-led growth is accepted in Malaysia.
\end{abstract}

Keywords: sustainable growth, tourist receipts, capital investment, tourism-led growth

\section{Introduction}

The tourism industry is one of the leading service industries and is considered a pivotal source of economic growth in the world economy. A developed and established tourism industry serves as the catalyst for national and regional development, helps establish the foreign exchange rate, creates more employment opportunities, and contributes to social development that will benefit the local community and tourists. The Malaysian tourism industry has received serious attention from the government since the 1980s because Malaysia was overly dependent on the primary and secondary sectors after it achieved its independence in 1957. Thus, the Ministry of Culture and Tourism was established in 1987 to diversify the economic risk by emphasizing the comparative advantage of the tourism industry. In 2013, the Ministry of Culture and Tourism was transformed into the Ministry of Tourism and Culture (MOTAC), which aims to promote Malaysia as a top-of-mind tourist destination.

The Malaysian tourism industry was the sixth largest contributor to the national account in 2014 (Mohsen, 2015a). This is one of the industries the government emphasizes in the Economic Transformation Programme (ETP) to strengthen and diversify economic risk. According to World Travel and Tourism Council (WTTC, 2015), the total contribution of Malaysian tourism to its gross domestic product (GDP) was $14.9 \%$ in 2014 . However, the total contribution of Malaysian tourism dropped to $9.8 \%$ of GDP in 2015 due to two airway incidents occurred in 2014 (Tourism Malaysia, 2016). Tourism industry showed the sign of recovery with an increase of $4.3 \%$ of tourist arrivals in 2016 after it slowed down in 2015 (Tourism Malaysia, 2017). It is believed that the Malaysian tourism has contributed significantly in generating national income. The total contribution of Malaysian tourism was RM182.4 billion or accounted $14.8 \%$ of national income (Department of Statistics Malaysia, 2017). Malaysian tourism is the third largest foreign income earner after manufacturing and palm oil industry in Malaysia which accounting for over 7.0\% of the country economy in 2016 (Misachi, 2017).

The total tourist receipts earned by the government in 2013 was RM65.4 billion, exceeding the initial target of RM65.0 billion (Tourism Malaysia, 2014). Furthermore, Tourism Malaysia (2015) reported that tourist receipts increased by $10.0 \%$ to RM72.0 billion due to the strong promotion of Visit Malaysia Year (VMY) in 2014. On 
the other hand, tourist receipts slightly declined to RM69.1 billion in 2015 (Tourism Malaysia, 2016). The reduction in total contribution to GDP, employment in the tourism industry, and tourist receipts may be due to the security issues in Sabah, airway incidents, and the slowdown in the global economy that affected tourists' arrivals in Malaysia in 2015. However, Tourism Malaysia (2016) stated that a fair comparison between years 2015 and 2013, in which despite there was no special financial allocation for promotion activities, the tourist receipts in 2015 had increased by $5.6 \%$ as compared with year 2013. Meanwhile, tourist receipts increased by $18.8 \%$ to RM82.1 billion in 2016 as compared to 2015 (Tourism Malaysia, 2017). The depreciation of Ringgit Malaysia has actually made shopping more affordable for foreign tourists to spend in Malaysia.

Tourist receipts and capital investment in the tourism industry are important components of enhancing sustainable growth in the tourism industry. This is because tourist receipts represent tourists' direct expenditures during their trips in the destination country. The tourism receipts constitute the revenue earned by the tourism industry and contribute significantly to the national income. The revenue earned by the government can be invested in the tourism industry or other industries to boost the country's economy in order to achieve its target as a high income economy status in 2020 . Hence, a variety of tourism packages has been launched and promoted to attract more local and international tourists. The purpose of capital investment in the tourism industry is to further the business objectives and such investment is expected to be productive across time. The tourism industry can become more competitive with greater capital investment. This industry involves many supporting industries in the value chain, such as transportation, accommodation, food and beverage, telecommunication, and recreation, and thus it can have a series benefits for the local economy, including economic growth and employment opportunities. Special event tourism needs capital investment by the government and non-government organizations (NGOs) to strengthen the positive effects of tourism on economic growth. Tourist receipts and tourist arrivals are important for tourism industry growth, but the most important impact of the Malaysian tourism industry is on the sustainable development of the economy and society (Mohsen, 2015b).

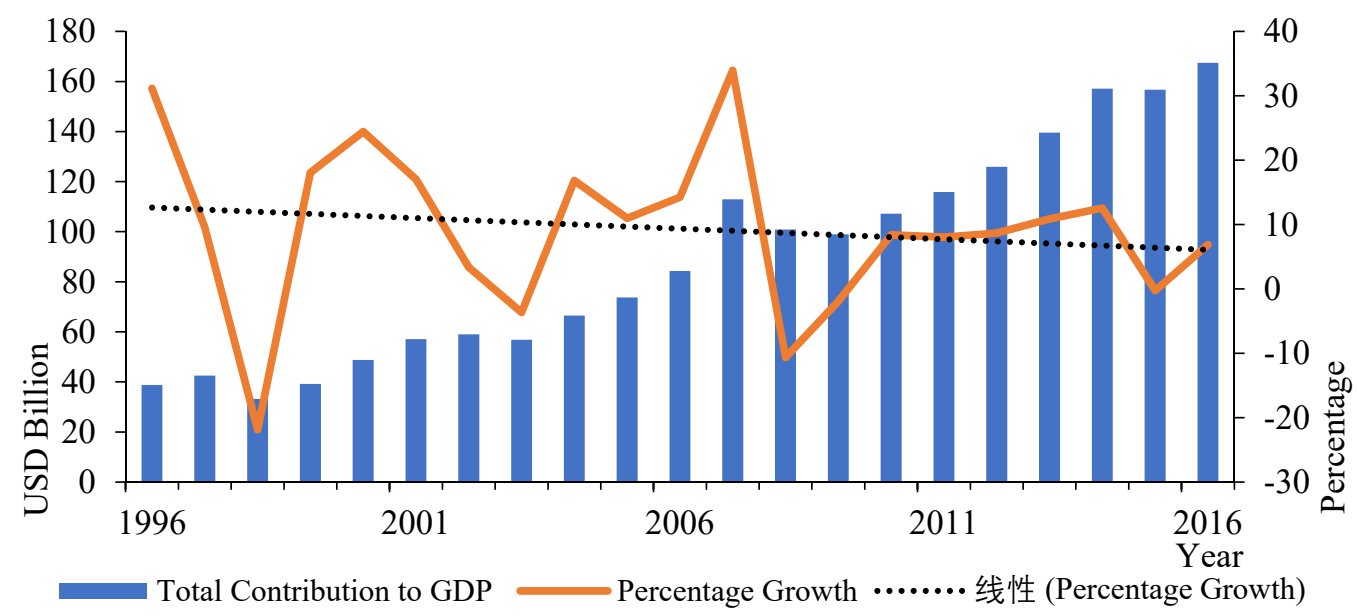

Figure 1. Tourism Contribution and Its Growth Rate to Malaysian GDP, 1996-2016

Figure 1 shows the total contribution of tourism industry to Malaysian GDP and its growth rate from 1996 to 2016. It is clearly shown that the contribution from tourism industry had increased steadily over time. However, it is noticeable that there were few sharp drops occurred in 1998 (-33.2\%), $2003(-3.7 \%), 2008(-10.7 \%), 2009$ $(-2.0 \%)$ and the latest drop being in $2015(-0.3 \%)$. These drops are due to Asian Financial Crisis, Severe Acute Respiratory Syndrome (SARS) outbreak, global financial crisis and local events such as the two airway incidents and security issues in Malaysia, respectively. As shown in Figure 1, the total contribution of tourism sector has increased over the years, however, the growth rate of this industry experienced a negative growth for the same period.

Nevertheless, tourism industry has its period of strong performance after the sharp falls such as in 1999 (18.1\%), 2004 (16.9\%), 2007 (34.0\%), 2010 (8.4\%), and 2016 (6.9\%) as presented in Figure 1. The figure shows that tourism industry has experienced volatile growth over the period which raise the needs to identify the impacts of this industry towards economic growth in Malaysia. Hence, this study aims to examine whether or not the tourism-led growth is valid in this study. 


\section{Literature Review}

In the study of tourism-led growth, tourist receipts have been utilized by a number of researchers, including Eugenio et al. (2004), Fayissa et al. (2008), Du et al. (2014), Bojanic and Lo (2016), Vita and Kyaw (2016), and Chiu and Yeh (2017), to determine their impacts on a country's economic growth. Their studies indicated that tourist receipts have a significant influence on economic growth. For example, Eugenio et al. (2004) stated that expenditure by foreign tourists can stimulate tourism development as well as human capital investment thus contributes significantly to economic growth. Fayissa et al. (2008) also discovered that tourist receipts have a significant effect on the income per capita growth rate in Africa. The impacts of tourism development on GDP growth vary for different countries at different levels of economic development, as Vita and Kyaw (2016) documented.

Chiu and Yeh (2017) reported that the tourism industry, with its comparative advantage, can stimulate overall economic growth. In contrast, development of the tourism industry may not stimulate economic growth if the industry has a comparative disadvantage. They further stated that more tourist receipts and arrivals may not necessarily lead to higher economic growth if the tourism industry faces a trade deficit and comparative disadvantage. This may be the reason why tourist receipts do not lead to economic growth in certain countries.

Capital investment spending in the tourism industry is another significant variable that stimulates economic growth. Capital investment means that the industries invested in human capital, land, and technology to further increase their productivity and profit maximization. Liu and Chen (2016) pointed out that increasing the government budget in fixed capital investment is one way to stimulate the economy. Kneller et al. (1999) mentioned that an increase in productive expenditure can significantly enhance the growth. They further stated that the government investment in transportation and communication produce positive outcome on growth. The physical capital is an important factor of growth in selected West African States (Salifou \& Haq, 2016). Eugenio et al. (2004) discovered that the tourism industry is conducive to economic growth in medium- and low-income countries but not necessarily in developed countries in Latin America. This is likely because the tourism goods and services in developing countries can better satisfy tourists' demand in terms of price and quality. Puah et al. (2014) reported that pricing strategy influences tourist expenditure behavior in Malaysia. In addition, Mbaiwa (2003) claimed that the establishment of tourism facilities, such as wholesale and retail industries, transportation, and camps, is influenced by the development of the tourism industry in the Okavango Delta. Development of the tourism industry promotes not only economic growth but also social development.

A recent study by Du et al. (2014) showed that increases in tourism activities are associated with increases in GDP. Thus, they suggested governments and NGOs must cooperate more frequently to launch a variety of tourism products to attract more tourist arrivals and encourage tourists to increase their spending in the travel destination. Ecotourism is one of the strengths of the Southeast Asia region and the member countries have agreed to promote ecotourism within this region (Ruekeith, 2014). As a result, the government can earn more revenue from tourist expenditures thus promote economic growth.

\section{Methodology and Data Description}

This study employs yearly data from 1995 through 2016. The data for real GDP (RGDP) and tourist receipts (TR) were collected from the World Development Indicators. However, the data for capital investment (CI) were obtained from the World Travel and Tourism Council (WTTC). Equation (1) is used to indicate the effect of TR and $\mathrm{CI}$ on RGDP in Malaysia:

$$
\mathrm{RGDP}=f(\mathrm{TR}, \mathrm{CI})
$$

where RGDP is obtained by dividing current GDP by the consumer price index (CPI), TR indicates the total international tourism receipts for the Malaysian tourism industry, and CI is the capital investment spending by all industries directly in the Malaysian tourism industry. Both TR and CI are expected to have a positive impact on RGDP, as suggested in most of the empirical literature.

A number of cointegration approaches such as Engle and Granger (1987), Johansen (1988), Johansen and Juselius (1990), Gregory and Hansen (1996), and Pesaran et al.'s (1999) Autoregressive Distributed Lag (ARDL) approach have been employed in the past studies. In this study, the ARDL technique introduced by Pesaran et al. (2001) was employed to identify whether the hypothesis of tourism-led growth exists in this empirical study. This technique has several advantages over other type of cointegration techniques. One of the main advantages is the ARDL technique can be applied for the study with a small sample size (Pesaran et al., 2001). Another advantage of this test is that it does not require pre-testing for unit roots to obviate the uncertainty associated 
with such tests (Pesaran et al., 2001). However, ARDL technique may not be valid for any data series which is generated by $I(2)$ or beyond because Pesaran et al. (2001) explicitly mentioned that the ARDL bounds test is subject to the assumption that the variables are integrated of order $I(0), I(1)$, or mutually cointegrated. Therefore, testing the level of stationarity is still necessary. The empirical model for this study is shown in equation (2):

$$
\begin{aligned}
\Delta \operatorname{InRGDP} P_{t}= & \alpha_{0}+\sum_{i=1}^{P} \alpha_{1} \Delta \operatorname{InR} G D P_{t-i}+\sum_{t=1}^{P} \alpha_{2} \Delta \operatorname{InTR} t_{t-i}+\sum_{t=1}^{P} \alpha_{3} \Delta \operatorname{InCI} t-i+\lambda_{1} \operatorname{InRGDP} P_{t-1} \\
& +\lambda_{2} \operatorname{InTR}_{t-1}+\lambda_{3} \operatorname{InCI}_{t-1}+\varepsilon_{t}
\end{aligned}
$$

\section{Findings and Discussions}

The stationary tests which are Augmented Dickey-Fuller (ADF) and Dickey-Fuller Generalized Least Squares (DFGLS) were applied to identify the level of stationarity and to ensure none of the variables are stationary at $I(2)$ in this study. Table 1 shows that all variables are stationary at $I(1)$. Therefore, ARDL technique was employed since our sample data cover a relatively short time and all variables are stationary at $I(1)$.

\begin{tabular}{|c|c|c|c|c|}
\hline & \multicolumn{4}{|c|}{ Test Statistics } \\
\hline & $\mathbf{t}_{\mu}$ & $\mathbf{t}_{\tau}$ & $\tau_{\mu}$ & $\tau_{\tau}$ \\
\hline \multicolumn{5}{|c|}{ A: Level } \\
\hline LRGDP & $-0.706(0)$ & $-2.213(0)$ & $-0.694(0)$ & $-2.075(0)$ \\
\hline LTR & $-0.813(0)$ & $-1.801(0)$ & $-0.574(1)$ & $-1.929(0)$ \\
\hline LCI & $-1.138(0)$ & $-2.048(2)$ & $-1.202(0)$ & $-2.440(0)$ \\
\hline \multicolumn{5}{|c|}{ B: First Differences } \\
\hline$\triangle \mathrm{LRGDP}$ & $-4.047(0)^{* * *}$ & $-4.000(0)^{* *}$ & $-4.050(0)^{* * *}$ & $-4.150(0)^{* * *}$ \\
\hline$\Delta \mathrm{LTR}$ & $-3.759(0)^{* *}$ & $-3.653(0)^{*}$ & $-3.842(0)^{* * *}$ & $-3.865(0)^{* * *}$ \\
\hline$\Delta \mathrm{LCI}$ & $-4.760(0)^{* * *}$ & $-4.695(0)^{* * *}$ & $-4.745(0)^{* * *}$ & $-4.947(0)^{* * *}$ \\
\hline
\end{tabular}

Table 1. Unit Root Tests Results

Notes. The $\mathrm{t}$ and $\tau$ statistics are for ADF and DFGLS, respectively. The subscript $\mu$ in the model allows a drift term while $\tau$ allows for a drift and deterministic trend. Asterisks $(* * *),(* *)$ and $(*)$ indicate statistically significant at $1 \%, 5 \%$ and $10 \%$ levels, respectively. Figures in parentheses are the lag lengths. Both the ADF and DFGLS tests examine the null hypothesis of a unit root against the stationary alternative. $\Delta$ denotes first difference operator.

In this section, we report the long run estimates of our model. The optimal lag length for estimation is selected using Akaike Information Criterion (AIC) that helps us in capturing the dynamic relationship to select the best model to estimate. The long run estimated ARDL model $(4,0,4)$ chosen by AIC is reported as follow:

$$
\mathrm{LRGDP}=5.218+0.220 \mathrm{LTR}+0.604 \mathrm{LCI}
$$

The empirical findings show that for the sample period under study, a $1 \%$ increase in tourist receipts increases real GDP by $0.2 \%$, while capital investment in the tourism industry provides a $0.6 \%$ increase. Both independent variables are positive and significantly related to real GDP.

Table 2. Granger Causality Test and Diagnostic Tests Results

\begin{tabular}{llllll}
\hline & \multicolumn{1}{c}{ LRGDP } & & \multicolumn{3}{c}{ Diagnostic Tests } \\
\hline LTR & $10.17(0.00)^{* * *}$ & JB & $1.37(0.50)$ & RESET [1] & $0.18(0.69)$ \\
LCI & $53.17(0.00)^{* * *}$ & BG [2] & $2.98(0.23)$ & CUSUM & Stable \\
ECT & $-0.87(0.00)^{* * *}$ & ARCH $[1]$ & $0.02(0.88)$ & CUSUM $^{2}$ & Stable $^{*}$
\end{tabular}

Notes. JB is the Jargue-Bera statistic for testing normality, BG indicates Breusch-Godfrey Serial Correlation LM Test to detect correlation error. ARCH and RESET are the ARCH effects for heteroskedasticity and Ramsey RESET specification test, respectively. CUSUM and CUSUM ${ }^{2}$ refer to CUSUM and CUSUM of squares stability tests. Asterisks (***) denote the rejection of null hypothesis at $1 \%$ significant level.

We then carried out the Granger causality test between the variables using Wald test. Table 2 reports the results for short run Granger causality test and diagnostic tests. The null hypothesis of no causal relationship between tourist receipts and capital investment is rejected at the $1 \%$ significance level. This indicates that these variables influence economic growth in Malaysia in the short run. The coefficient of the error-correction term (ECT) is negative and statistically significant at $1 \%$ level. It shows that the disequilibrium among the variables needs 
approximately one year and two months to adjust to the equilibrium state. Table 2 also indicates that the model passes all the diagnostic tests. Hence, the model is satisfactory in terms of goodness-of-fit; the estimated residuals are normally distributed with constant variances, well-specified, and free from serial correlation. Furthermore, the CUSUM (cumulative sum of recursive residuals) and CUSUM of squares stability tests indicate that the model is stable within the period of the study.

\section{Conclusion}

Tourist receipts and capital investment in the tourism industry were employed in this study to determine their empirical effects on growth in the Malaysian economy. The empirical results show that tourist receipts and capital investment in the tourism industry have significant positive impacts on economic growth in Malaysia. This implies that the hypothesis of tourism-led growth does exist in Malaysia. The allocation of capital investments in the tourism industry is important to ensure that the industry's growth is sustainable and that resources are used at the optimum level. Human capital investment in the tourism industry is also important because the tourism industry directly and indirectly involves industries that require different types of human resources. For example, Jolliffe and Baum (2004) and Formadi and Mayer (2009) stated that event management requires multiple skills, including professional, managerial, cognitive, and soft skills.

The tourism players should design a variety of tourism products, promotional campaigns, and special events such as food festivals and cultural events that reflect and represent the uniqueness of the Malaysian tourism industry. In addition, the decision makers have to be aware of all the factors that play a role in the development process in order to avoid or minimize the undesirable impacts (Stankova, 2010). Information on Malaysian tourism, including special events, festivals, and tourist spots, should also be updated from time to time. The authorities can utilize online social media or mobile phone apps to promote tourism activities because the Internet is one of the most common and useful tools for the public to search for information and plan trips.

The government may use more E-visas and sign more travel treaties with other countries in the region, such as Association of Southeast Asian Nations (ASEAN) member countries, to encourage their citizens to visit Malaysia. The ASEAN region contributed $75.8 \%$ of the total tourist arrivals in Malaysia by 2016 (Tourism Malaysia, 2017). A closer and strategic collaboration with neighboring countries can further stimulate the cross-border tourism and, hence, generate employment opportunities, income, and local linkages among economic activities.

\section{Acknowledgments}

Financial support from Fundamental Research Grant Scheme [FRGS/SS01(01)/1292/2015(09)] is gratefully acknowledged.

\section{References}

Bojanic, D. C., \& Lo, M. (2016). A comparison of the moderating effect of tourism reliance on the economic development for islands and other countries. Tourism Management, 53, 207-214. https://doi.org/10.1016/j.tourman.2015.10.006

Chiu, Y. B., \& Yeh, L. T. (2017). The threshold effects of the tourism-led growth hypothesis: Evidence from a cross-sectional model. Journal of Travel Research, 56(5), 625-637. https://doi.org/10.1177/0047287516650938

Department of Statistics Malaysia. (2017). Tourism Satellite Account 2016. Putrajaya, Malaysia: Department of Statistics Malaysia.

Du, D., Lew, A. A., \& Ng, P. T. (2014). Tourism and economic growth. Journal of Travel Research, 55(4), 454-464. https://doi.org/10.1177/0047287514563167

Engle, R. F., \& Granger, C. J. (1987). Co-intergration and error correction: Representation, estimation, and testing. Econometrica, 55(2), 251-276.

Eugenio, M. J., Morales, N. M., \& Scarpa, R. (September 2004). Tourism and economic growth in Latin American countries: A panel data approach. International Conference on Tourism and Sustainable Economic Development - Macro and Micro Economic Issues. Sardinia, Italy.

Fayissa, B., Nsiah, C., \& Tadasse, B. (2008). Impact of tourism on economic growth and development in Africa. Tourism Economics, 14(4), 807-818. https://doi.org/10.5367/000000008786440229

Formadi, K., \& Mayer, P. (2009). Employee's value anticipation in event management. Journal of Tourism Challenges and Trends, 2(2), 115-127. 
Gregory, A. W., \& Hansen, B. E. (1996). Residual-based tests for cointegration in models with regime shifts. Journal of Econometrics, 70(1), 99-126. https://doi.org/10.1016/0304-4076(69)41685-7

Johansen, S. (1988). Statistical analysis of cointegration vectors. Journal of Economic Dynamics and Control, 12(2-3), 231-254. https://doi.org/10.1016/0165-1889(88)90041-3

Johansen, S., \& Juselius, K. (1990). Maximum likelihood estimation and inference on cointegration - with applications to the demand for money. Oxford Bulletin of Economics and Statistics, 52(2), 169-210. https://doi.org/10.1111/j.1468-0084.1990.mp52002003.x

Jolliffe, L., \& Baum, T. (2004). Event tourism partnership evolution - Evidence from the Highlands of Scotland. Tourism Today, 4(3), 7-20.

Kneller, R., Bleaney, M. F., \& Gemmell, N. (1999). Fiscal policy and growth: Evidence from OECD countries. Public Economics, 74(2), 171-190. https://doi.org/10.1016/S0047-2727(99)00022-5

Liu, Z. J., \& Chen, Y. Y. (2016). The investment choices to deal with the slowdown in economic growth - Based on the analysis of the effect of human capital investment. Open Journal of Business and Management, 4, 558-570. 10.4236/ojbm.2016.44060

Mbaiwa, J. E. (2003). The socio-economic and environmental impacts of tourism development on the Okavango Delta, north-western Botswana. Journal of Arid Environments, 54(2), 447-467. https://www.sciencedirect.com/science/article/pii/S0140196302911018

Misachi, J. (2017, August 1). Top source countries of tourists to Malaysia. Retrieved from Worldatlas: http://www.worldatlas.com/articles/top-source-countries-of-tourists-to-malaysia.html

Mohsen, A. S. (2015a, October 19). Tourism industry now 6th largest GDP contributor, says Najib. Retrieved from The Sun Daily: http://www.thesundaily.my/news/1586311

Mohsen, A. S. (2015b, October 20). More jobs and investments in KL tourism by 2025. Retrieved from The Sun Daily: http://www.thesundaily.my/news/1587166

Pesaran, M. H., Shin, Y., \& Smith, R. J. (2001). Bound testing approaches to the analysis of level relationships. Journal of Applied Econometrics, 16(3), 289-326. https://doi.org/10.1002/jae.616

Pesaran, M. H., Shin, Y., \& Smith, R. P. (1999). Pooled mean group estimation of dynamic heterogeneous panels. Journal of the American Statistical Association, 94(446), 621-634. https://www.jstor.org/stable/2670182

Puah, C. H., Thien, F. T., \& Arip, M. A. (2014). Singaporean demand for tourism in Malaysia. Economic Annals-XXI, 11(12), 32-36.

Ruekeith, G. O. (2014, September 6). EATOF members sign declaration to jointly promote tourism, especially eco-tourism. Retrieved from The Borneo Post: http://www.theborneopost.com/2014/09/06/eatof-members -sign-declaration-to-jointly-promote-tourism-especially-eco-tourism/

Salifou, C. K., \& Haq, I. U. (2016). Tourism, globalization and economic growth: A panel cointegration analysis for selected West African States. Current Issues in Tourism, 20(6), 664-667. https://doi.org/10.1080/13683500.2016.1175421

Stankova, M. (2010). Diversification of rural tourism trough partnership approaches in Eastern Europe destination. Perspectives of Innovations, Economics and Business, 5(2), 30-32.

Tourism Malaysia. (2014, February 28). Malaysia registers 25.7 million tourists and RM65.44 billion tourist receipts in 2013. Retrieved from Tourism Malaysia: http://www.tourism.gov.my/media/view/malaysia -registers-25-7-million-tourists-and-rm65-44-billion-tourist-receipts-in-2013

Tourism Malaysia. (2015, March 31). Malaysia's 2014 tourist arrivals grow 6.7\%. Retrieved from Tourism Malaysia: http://www.tourism.gov.my/media/view/malaysia-s-2014-tourist-arrivals-grow-6-7

Tourism Malaysia. (2016, March 31). Malaysia registers 25.7 million tourists in 2015. Retrieved from Tourism Malaysia: http://www.tourism.gov.my/media/view/malaysia-registers-25-7-million-tourists-in-2015

Tourism Malaysia. (2017, March 13). Malaysia's 2016 tourist arrivals grow 4.0\%. Retrieved from Tourism Malaysia: http://www.tourism.gov.my/media/view/malaysia-s-2016-tourist-arrivals-grow-4-0

Vita, G. D., \& Kyaw, K. S. (2016). Tourism development and growth. Annals of Tourism Research, 60, 23-26. http://dx.doi.org/10.1016/j.annals.2016.05.011

World Travel and Tourism Council (WTTC). (2015). Travel and Tourism: Economic Impact 2015 Malaysia. 
London, UK: World Travel and Tourism Council.

\section{Copyrights}

Copyright for this article is retained by the author(s), with first publication rights granted to the journal.

This is an open-access article distributed under the terms and conditions of the Creative Commons Attribution license (http://creativecommons.org/licenses/by/4.0/). 